\title{
Analysis of the impact of the parameters of outside air on the condition of indoor air
}

\author{
E. Zender - Świercz ${ }^{1}$
}

Received: 13 May 2016/Revised: 2 December 2016/Accepted: 6 February 2017/Published online: 18 February 2017

(C) The Author(s) 2017. This article is published with open access at Springerlink.com

\begin{abstract}
The article presents the impact of external conditions on the parameters of the air inside the flats and hybrid ventilation. In the vast majority of existing multifamily buildings, as well as in many newly built ones, the way of air exchange is natural ventilation. The air exchange in this system is the result of the temperature difference in the outside of the building and in the ventilation duct as well as the pressure difference caused by the wind. The way to strengthen the exchange of indoor air is to use the hybrid ventilation by using a fan to assist natural air flow in the "no wind" periods. When designing the natural ventilation installation, the extreme conditions outside the building are assumed, not including air parameters changing. This article attempts to identify the conditions of atmospheric air which cause the disturbances of exchange indoor air and it attempts to decide when a fan should work to assist natural ventilation.
\end{abstract}

Keywords Building ventilation · Air quality $\cdot$ Wind parameters $\cdot$ Carbon dioxide concentration

Editorial responsibility: M. Yassin.

E. Zender - Świercz

ezender@tu.kielce.pl

1 Department of Building Physics and Renewable Energy, Faculty of Environmental, Geomatics and Energy Engineering, Kielce University of Technology, Kielce, Poland

\section{Introduction}

Interior microclimate has a significant impact on the well-being and people's health. In the bibliography, you can find a description of the air quality depending on the applied ventilation (Muller and Skrzyniowska 2012). Unfortunately, for most residents, the energy efficiency of a building associated with the lower cost of its maintenance is more important than the proper functioning of the ventilation system, which has a significant impact on human health and the building structure.

The vast majority of buildings in Poland are equipped with natural ventilation. The air passes through the natural ventilation ducts, and it inflows through the building's leaks. The usage of sealed windows and doors as well as the buildings insulation leads to air infiltration disorders. An increasingly prevalent way to increase the air exchange is to use the hybrid fan mounted on the outlet duct of natural ventilation with the intension to use it in case of the channel insufficient pressure.

Improper air exchange is associated with sick building syndrome. Users complain about tiredness, headache and immunity weakness. None or improper ventilation system also affects the building structure. There is also mold appearance observed in the building which affects not only residents but is also destructive to the partitions.

The amount of air flowing in and out of the building is affected not only by the building structure and the applied installation, but also by the external environment: wind speed and direction, the temperature and the air pressure. In the bibliography, one can find the mathematical models, which take into account the flow of air as a result of wind (Piotrowski et al. 2015), 
however, concerning the air exchange of the ventilated roofs' spaces not the living area inside. In the article (Zender - Świercz and Piotrowski 2011), an attempt was made to create a mathematical model of the wind speed and wind direction impact on the interior microclimate of residential buildings. The analysis covered flats in multifamily four-story buildings located in the city in the temperate climate in the third climatic zone. The study was conducted over the years 2010-2014. For the analysis data from the winter months, i.e., December, January, February were selected.

\section{Materials and methods}

\section{Subject of the study}

The flats in multifamily buildings equipped with natural ventilation and the air supply additional ducts were analyzed. The buildings were insulated, and the flats were equipped with tight windows and doors. During the construction phase, the lower sections of natural ventilation ducts (normally not for use) are used as air supply ducts. The apartments were equipped with grilles on these ducts. The wall air intake was mounted on the duct, and it was located on the building wall $2 \mathrm{~m}$ above ground level. The ducts were placed at the underground garage level and they provided the air gravitationally to the vertical ducts of natural ventilation and then to the analyzed apartments.

Outside air flows into the lower sections of the natural ventilation ducts (normally not in use), which is presented in Fig. 1. In the vertical duct of natural ventilation, the sealed diaphragm was mounted. It separates the supply and exhaust air stream in one duct.
The supply and exhaust vents are placed in different rooms. The air flows into the hall. Above the inflow grille, the diaphragm was mounted, and above this diaphragm, the outflow grille was located (on the opposite side to the inflow). The air flows out of the bathroom and the kitchen where the exhaust grilles are mounted.

The air is supplied to flats also through the leaks. This flow is caused by the wind. The air is supplied to the bedroom through the door between the hall and this room. The analyzed objects are the residential buildings where the main source of pollution is humans. "Emissions of carbon dioxide is (...) correlated with the emission of bioparticles and, therefore the easily measured $\mathrm{CO}_{2}$ is very often regarded as an indicator of the total emissions from the human" (Sowa and Bartkiewicz 1997). Therefore, among many others, it is the most reliable indicator of air quality in the analyzed object (Śliwowski 2000; PN-EN ISO 7730). This is a criterion commonly used for many years. It is possible to detect even at low concentrations, so it was used in the tests for the analysis of the internal microclimate. The $\mathrm{CO}_{2}$ concentration was measured in two rooms: a bedroom and a hall. The preliminary air quality results in the multifamily buildings were presented in bibliography (Piotrowski and Zender - Świercz 2008; Piotrowski et al. 2008; Zender - Świercz and Piotrowski 2008, 2009, 2010).

\section{The way of measuring}

In order to determine the building air-tightness, the BlowerDoor measurement method was used. All the holes and slots (except windows) in the rooms were covered. The pressurization (50 $\mathrm{Pa}$ ) and depressurization (50 $\mathrm{Pa}$ ) were performed according to standards (PN-EN 13829).
Fig. 1 Simplified diagram of an analyzed ventilation system (Zender - Świercz 2012)

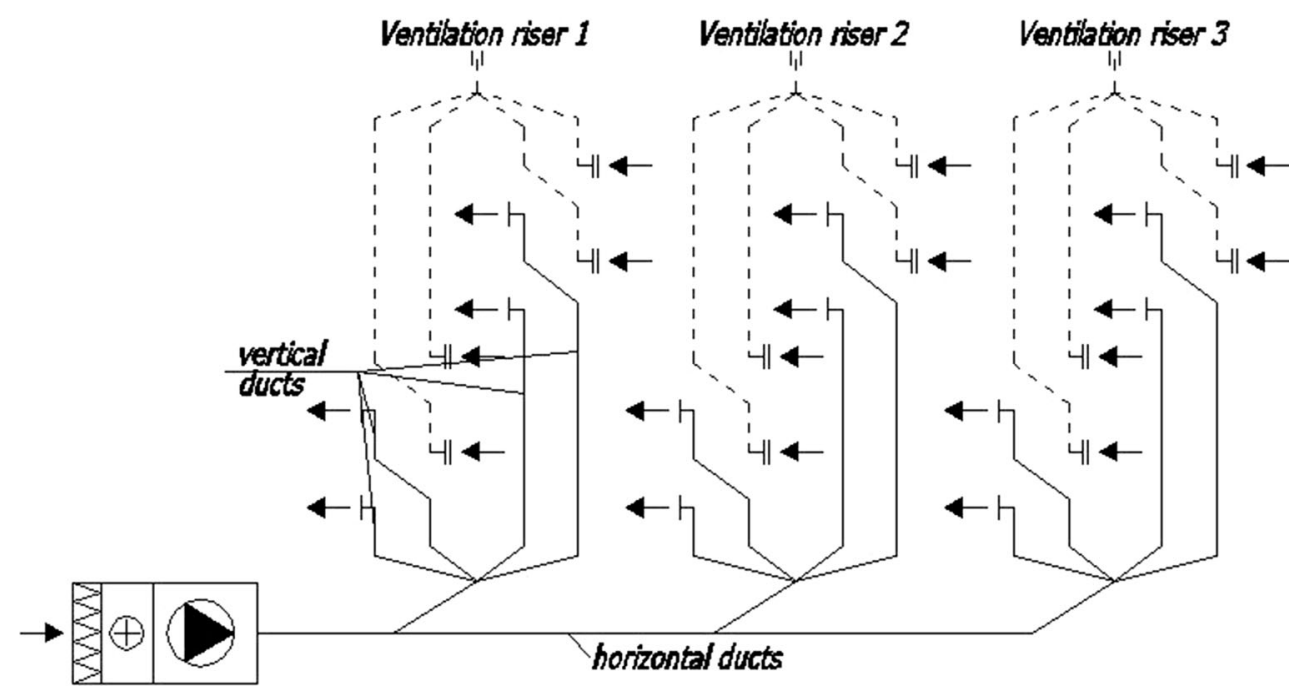


Table 1 Measurement ranges of indoor air quality monitor

\begin{tabular}{lll}
\hline The carbon dioxide concentration & $0-5000$ & $\mathrm{ppm}$ \\
Relative humidity & $0-100$ & $\%$ \\
Air temperature & $10-45$ & ${ }^{\circ} \mathrm{C}$ \\
Barometric pressure & $900-1100$ & $\mathrm{hPa}$
\end{tabular}

(Zender - Świercz 2012)

Table 2 Display resolution of indoor air quality monitor

\begin{tabular}{lll}
\hline The carbon dioxide concentration & 1 & $\mathrm{ppm}$ \\
Relative humidity & 0.1 & $\%$ \\
Air temperature & 0.1 & ${ }^{\circ} \mathrm{C}$ \\
Barometric pressure & 1 & $\mathrm{hPa}$ \\
\hline
\end{tabular}

(Zender - Świercz 2012)

In order to determine conditions in the room, the following parameters were measured: carbon dioxide concentration, relative humidity, air temperature and barometric pressure by using an indoor air quality monitors.

To measure the $\mathrm{CO}_{2}$ concentration, a double-beam detector was applied which uses a dependence of attenuation a specific band of infrared radiation from the carbon dioxide concentration.

To measure the temperature and humidity miniature, solid-state sensor was used.

Table 1 shows the measuring range for each parameter. Table 2 presents the resolution for each indication.

The measurements were taken during the winter. Research positions were arranged in each flat. The air quality monitors were set in each of them. The measurement results were recorded continuously. Value recorded for the same speed of the outside air (analogous for the outside air temperature) was selected from the acquired data. The obtained data sets were used to calculate arithmetic means.

The idea of the analysis was to find the average value of $\mathrm{CO}_{2}$ for each air speed value (air temperature value).

\section{Results and discussion}

The trend approximation of the empirical data was made using the exponential model. For this model, the highest compatibility with the data was observed. Due to the fact that the studies were conducted under real conditions sometimes significant differences were observed between apartments.

\section{The dependence of $\mathrm{CO}_{2}$ concentration on the temperature}

The amount of carbon dioxide is presented as the average value for the same wind speed and duration of the day and season. The results are presented in graphs according to the wind direction (Fig. 2). The outside air temperature, wind speed and direction were determined in the meteorological station.

The most preferred period of the year, according to the analysis, is winter. In this period, the impact of confounding factors is smallest (e.g., opening the windows by residents).

During the measurements, there were no winds from the South. During the analysis of $\mathrm{CO}_{2}$ concentration, taking into account average wind speed, the decrease in $\mathrm{CO}_{2}$ concentration with growth of temperature was observed when the wind was blowing from the North and West. When the wind direction was from the East, the concentration of $\mathrm{CO}_{2}$ in the least was dependent on the outside air temperature and reached the lowest values. Detailed analysis has shown that at low wind speed of $1 \mathrm{~m} / \mathrm{s}$, for all wind directions the $\mathrm{CO}_{2}$ concentration increases. At the wind speed of $2 \mathrm{~m} / \mathrm{s}$, from the North and from the East, a slight decrease in the concentration of $\mathrm{CO}_{2}$ was observed. And at wind from the West, the almost constant value of analyzed parameter was recorded. At higher wind speeds for all wind directions, the $\mathrm{CO}_{2}$ concentration decreased with increasing temperature.

The lowest values of the analyzed gas concentrations were observed for the highest wind speed.

The measurements away from the trend line may indicate a momentary disruption that may have occurred sometimes. This could be opening the windows by users or covering the ventilation outlet.

The above analysis shows the improvement of air quality with the increased air temperature regardless of the wind direction. It means that the wind has a greater impact on the air inflow and outflow from the room rather than the temperature. It is important that it should be included in the calculation of natural ventilation and hybrid one when selecting a fan. This is confirmed by the analysis presented in (Yang and Li 2015) for high buildings, and (Turner and Awbi 2015) where the authors have noticed the influence of wind parameters; however, it was not the basis of the analysis carried out by them. In the article (Rong et al. 2015), the authors also agreed on the need to take into account the effect of wind on the ventilation system, but their analysis is not related to residential buildings.

Higher carbon dioxide concentrations at very low ambient temperatures may be related to the covering of the 
Fig. 2 Change in the average value of carbon dioxide $\left(\mathrm{CO}_{2}\right)$ concentration with an average temperature of the outside air, depending on wind speed for different wind directions. Natural ventilation. Winter
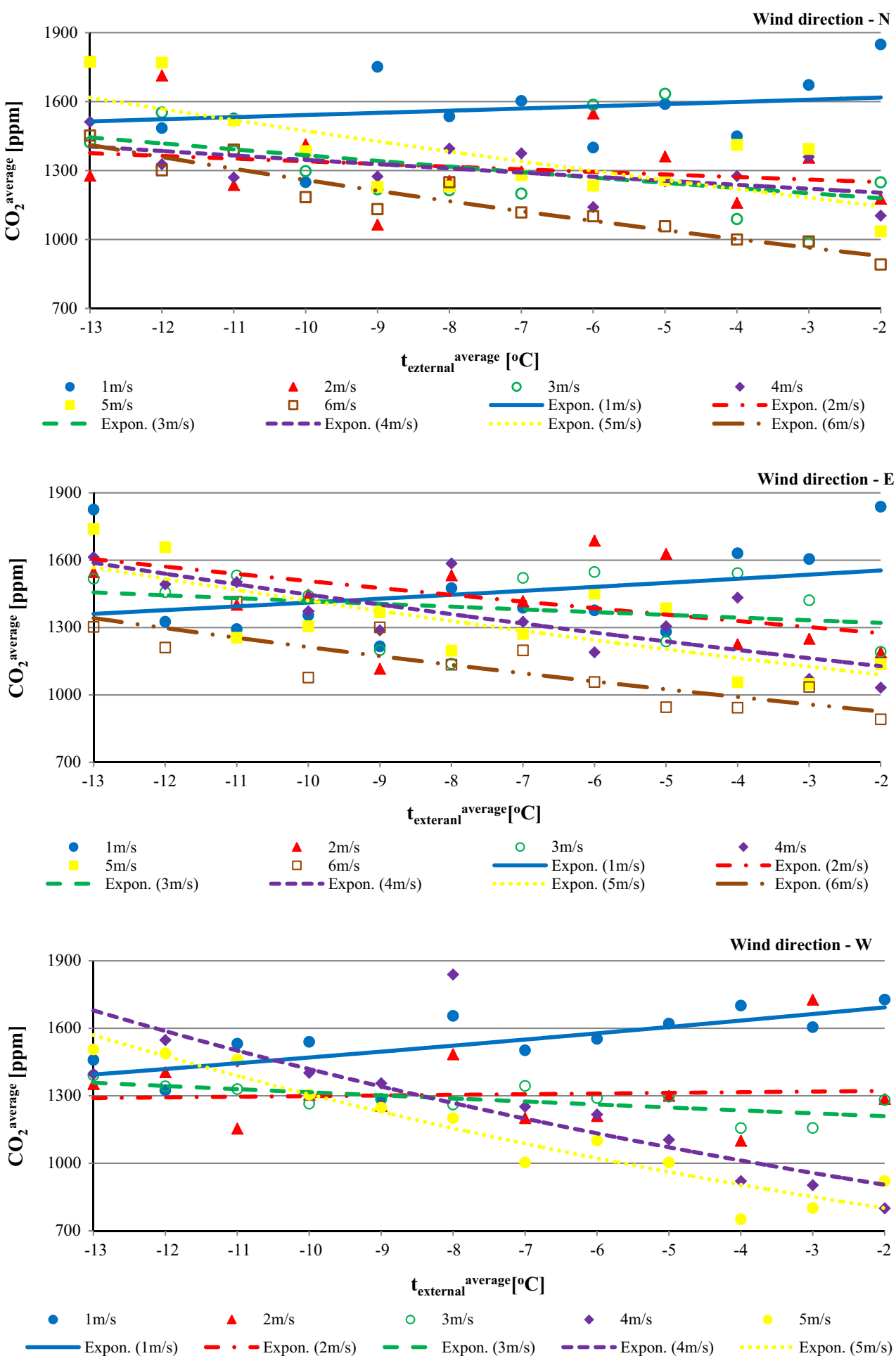
Fig. 3 Change in the average value of the carbon dioxide $\left(\mathrm{CO}_{2}\right)$ concentration with an average wind speed, depending on temperature of the outside air for different wind directions. Natural ventilation. Winter
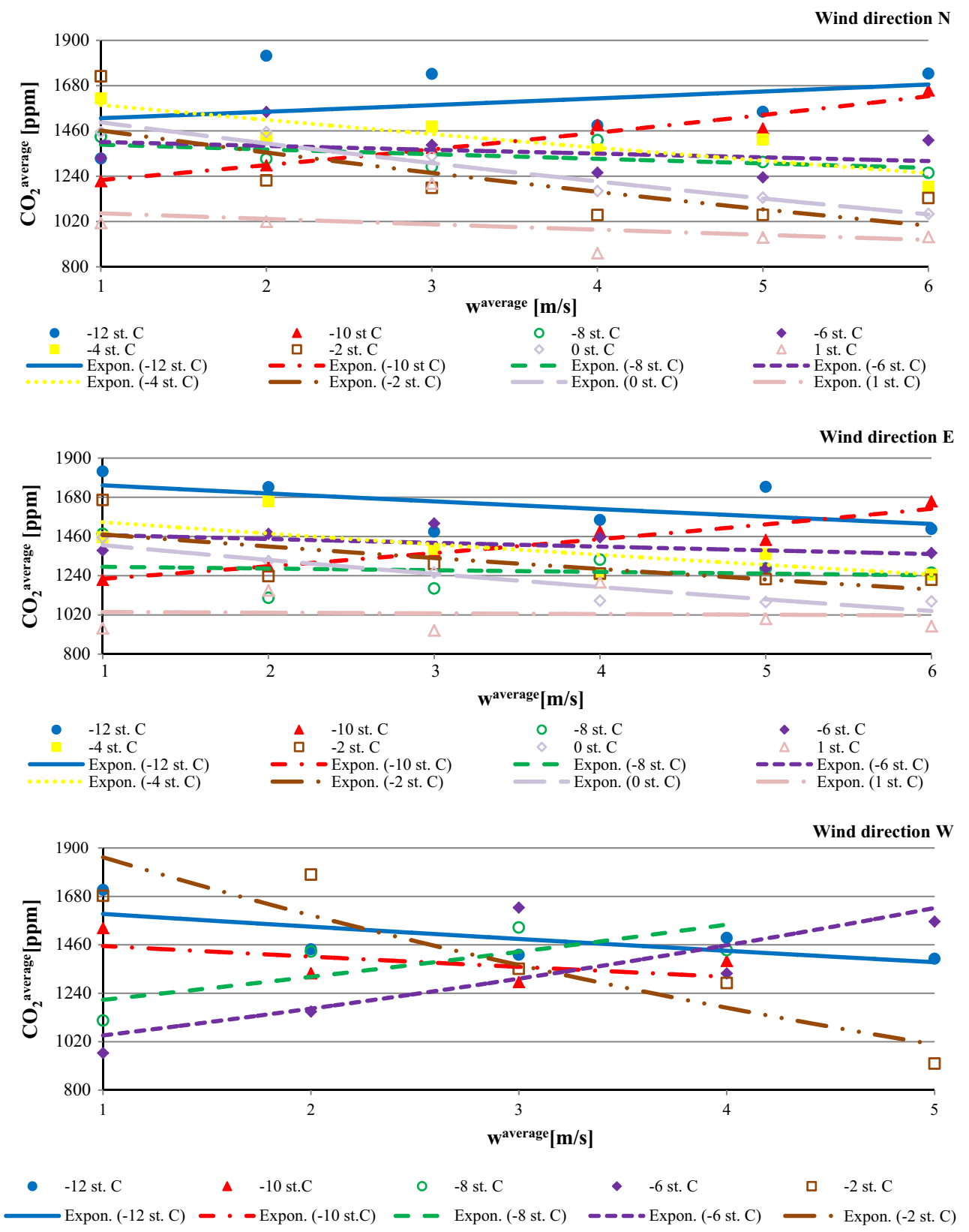

ventilation grilles by residents which leads to reduced air exchange. Residents, because of the low infiltrating air temperature and lack of knowledge about correct functioning of natural ventilation, were covering the window vents and grilles and reduced the power of the heating system instead of compensating the low temperature by heating system.

\section{The impact of the wind speed on the $\mathrm{CO}_{2}$ concentration}

The impact of the wind speed on the $\mathrm{CO}_{2}$ concentration was shown in the graphs (Fig. 3). The concentration of $\mathrm{CO}_{2}$ in the form of average value has been determined for the same outside air temperature and the period of the day 
and season. The analysis covered, as before, various wind directions.

Analyzing the average value of outside temperature, a decrease in $\mathrm{CO}_{2}$ concentration with increased wind speed for all direction was observed. Detailed analysis showed an increase in the concentration of $\mathrm{CO}_{2}$ with increasing speed of the wind from the North at a low outside temperature $\left(-12\right.$ and $\left.10{ }^{\circ} \mathrm{C}\right)$. The $\mathrm{CO}_{2}$ concentration also increased with increased wind speed when the Eastern wind at the temperature of $-10^{\circ} \mathrm{C}$ and the Western wind at the temperature -8 and $-6{ }^{\circ} \mathrm{C}$ occurred. This means that at that time the apartment was not ventilated enough. It could be a result of covering the ventilation grilles by residents or changes in aerodynamic coefficient. No matter what the wind direction was, for the remaining outside temperature, the decrease in carbon dioxide concentration with an increase in wind speed was observed.

Detailed analysis, which takes into account the apartments location on different floors of the building, showed that the apartment where a decreased $\mathrm{CO}_{2}$ concentration with increased wind speed occurred at low temperatures are on the lower floors (first and second floor). This means that the pressure in ventilation duct is higher. As we know, the higher air pressure the better the air exchange is. This means that at higher levels greater impact on the amount of air flowing in and out from the room is due to the wind rather than the outside temperature. Therefore, in the ventilation system calculation, we must also take into account the external air movement.

\section{The dependence of the wind direction on the $\mathrm{CO}_{2}$ concentration}

The analyses of the correlation between the carbon dioxide concentration and the wind direction were made. The results of them are presented in the graphs (Fig. 4).

The observations show that the smallest value of the analyzed parameter occurred with the wind from the West. For low outdoor air temperature $-13{ }^{\circ} \mathrm{C}$, the $\mathrm{CO}_{2}$ concentration decreased with wind speed for the wind from the East. For other directions, an increase in the gas concentration was observed. It is worth mentioning that the air intake was located on the Western side. This means that in
Fig. 4 Correlation between the $\mathrm{CO}_{2}$ concentration and the wind speed depending on its direction

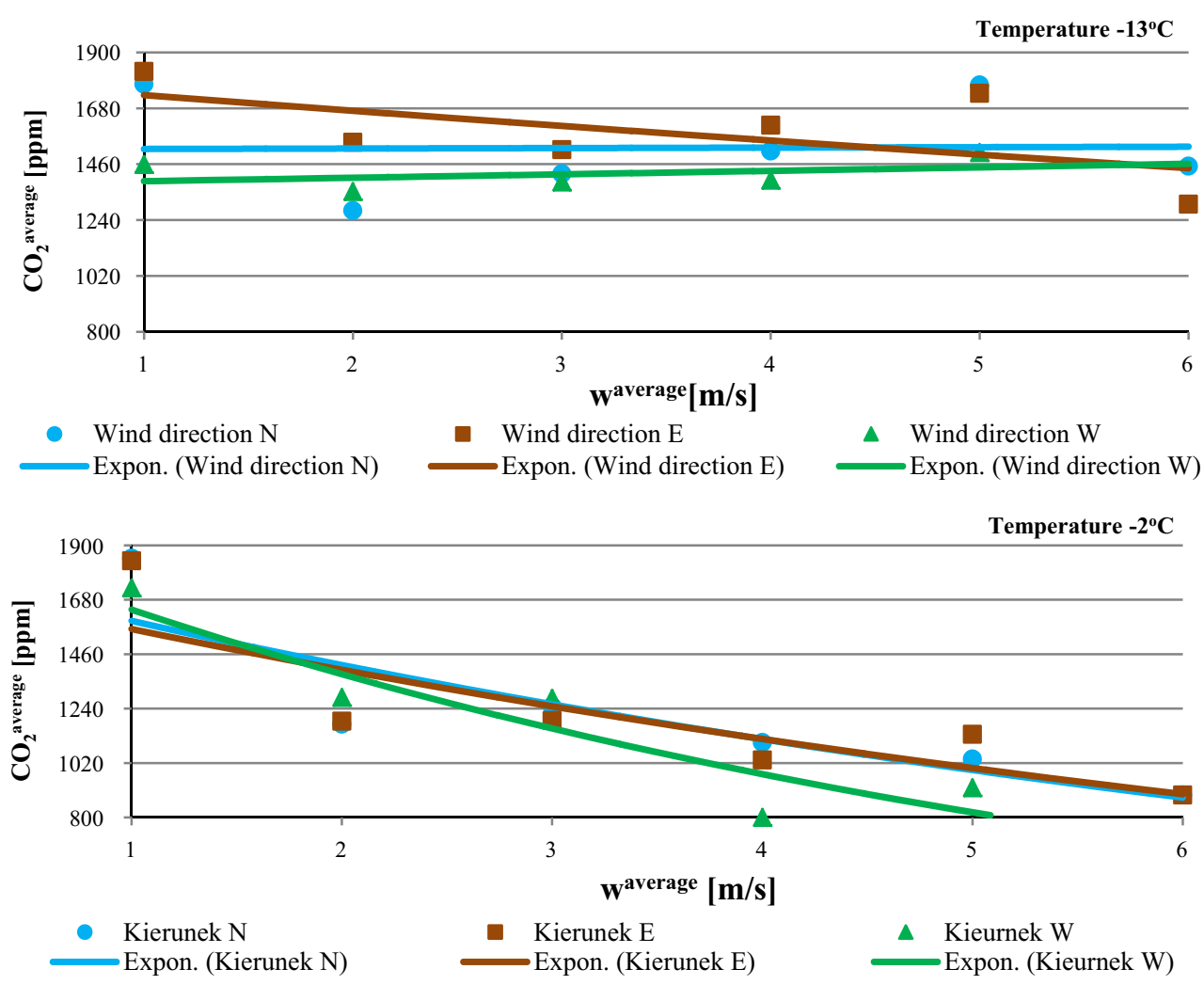


the case of wind from this direction the largest amount of fresh air was pressed into the building and, therefore, the lowest value of $\mathrm{CO}_{2}$ concentration was reached. Simultaneously, the temperature and humidity of indoor air were measured, and both parameters were in the comfort range.

At the outside air temperature of $-2{ }^{\circ} \mathrm{C}$, for all wind directions, decrease in the $\mathrm{CO}_{2}$ concentration with the increase in wind speed was observed.

At low wind speeds, the $\mathrm{CO}_{2}$ concentration level was less dependent on the temperature. At higher wind speeds, the $\mathrm{CO}_{2}$ concentration decreased with temperature and the higher the speed the greater this decrease was.

Such analysis of the results suggests a greater residents' influence on the building functioning at low outside temperatures because of the rooms cooling by infiltration of air through the window slots. When the wind blows from the direction where the air intake is installed, the stream flowing into the room has a higher temperature (after flowing on the garage level and vertical ducts of natural ventilation) rather than the stream flowing in by the infiltration. In addition, the location of the supply grilles in the hall is advantageous because of the low frequency of people staying there and greater clothing insulation (a person close to the grilles is dressed in the external clothes).

\section{Conclusion}

The analysis of the outdoor air parameters' impact on the indoor air showed an improvement of indoor air quality with increased outdoor air temperature. Only at low wind speed $(1 \mathrm{~m} / \mathrm{s})$, the opposite trend was recorded. The decreasing $\mathrm{CO}_{2}$ concentration with increased wind speed was observed for all wind directions. Only at very low temperatures and the wind from the North, the microclimate in rooms deteriorated. The analysis was carried out during normal flats functioning; thus, deviation from a trend which appear in the analysis may have been due to the residents actions. Tests allow to explicitly state that wind velocity has a greater impact on the indoor air quality than outdoor air temperature. This was particularly evident in the apartments on the top floors, where the pressure in gravity duct is lower. The air intake was located on the Western side, and windows were located on the Western and Eastern side. Analysis showed lower concentrations of $\mathrm{CO}_{2}$ when wind was blowing from the West. Hence, the conclusion that when wind occurred from the East, the residents cover the window vents due to the low temperature of the infiltrating air. Temperature of the air flowing through the duct of the analyzed system was higher than the outside air temperature, and therefore the interference of residents were smaller. Residents, instead of compensating the low temperature by the heating system, covered the window vents and grilles. It was because of financial savings.

Analysis of the impact of the wind direction on indoor air quality dictates the need for external parameters' measurements before buildings are designed. The buildings should be located in such sites with windows and doors placed on the wind blows side. This will allow for a greater fresh air flow and a reduction in the hybrid fan working frequency. In addition, the lower section of natural ventilation ducts used in the way presented in the analysis allows to reduce the degree of apartments cooling, thus reducing the likelihood of the users interference with the building functioning. In this case, it must also be taken into account that the location of the air intakes should be on the windward side. Such a solution will enhance the air exchange, reduce the frequency of switching on the fan of a hybrid ventilation (in the case of its use for exhaust ducts) and raise the temperature of the air inflowing to the flats.

Acknowledgements The research was co-funded by European Regional Development Fund under the Innovative Economy Operational Programme. Project title: Innovative measures and effective methods to improve the safety and durability of buildings and transport infrastructure in the sustainable development strategy (Number of Grant: PO IG 01.01.02-10-106/09-00).

Open Access This article is distributed under the terms of the Creative Commons Attribution 4.0 International License (http:// creativecommons.org/licenses/by/4.0/), which permits unrestricted use, distribution, and reproduction in any medium, provided you give appropriate credit to the original author(s) and the source, provide a link to the Creative Commons license, and indicate if changes were made.

\section{References}

Muller J, Skrzyniowska D (2012) Air quality and room ventilation (in polish). Czasopismo Techniczne (Technical Transactions) Issue 28 Środowisko (Environment Engineering) Issue - 4 Ś, Krakow p 37-49

Piotrowski JZ, Zender - Świercz E (2008) The results of applying individual supply air system in the premises where the bifunctional boilers installed (in Polish). Instal 12/2008, Warsaw, p 29-30

Piotrowski JZ, Zender - Świercz E, Telejko M (2008) Research into indoor microclimate in flats with individual systems of air intake in view of energy saving in buildings. In: SolPol 2008, international conference, renewable energy innovative technologies and new ideas, Warsaw

Piotrowski JZ, Stroy A, Olenets M (2015) Mathematical model of the thermal-air regime of a ventilated attic. J Civil Eng Manag 21(6):710-719

PN-EN 13829 Thermal performance of buildings-determination of air permeability of buildings - fan pressurization method

PN-EN ISO 7730 Moderate thermal environments-determination of the PMV and PPD indices and specification of the conditions for thermal comfort 
Rong L, Liu D, Pedersen EF, Zhang G (2015) The effect of wind speed and direction and surrounding maize on hybrid ventilation in a dairy cow building in Denmark. Energy Build 86:25-34

Śliwowski L (2000) Interior microclimate and thermal comfort of people in rooms (in Polish). Oficyna Wydawnicza Politechniki Wrocławskiej (Publisher University of Technology in Wroclaw), Wroclaw

Sowa J, Bartkiewicz P (1997) The concentration of carbon dioxide as a source of information about indoor air quality (in Polish). In: Materiały konferencyjne 6 konferencji naukowo - technicznej (Conference materials 6th conference of scientific - technical), Lodz, p 336

Turner WJN, Awbi HB (2015) Experimental investigation into the thermal performance of a residential hybrid ventilation system. Appl Therm Eng 77:142-152

Yang D, Li P (2015) Dimensionless design approach, applicability and energy performance of stack-based hybrid ventilation for multi-story buildings. Energy Part 1 93:128-140
Zender - Świercz E (2012) Adjusting the microclimate parameters by the individual system of air intake. Dissertation, Kielce University of Technology

Zender - Świercz E, Piotrowski JZ (2008) Microclimate in rooms with the individual system of air intake. Indoor Air 2008. In: The 11th international conference on indoor air quality and climate, Copenhagen, Denmark

Zender - Świercz E, Piotrowski JZ (2009) Elimination of the negative influence of tight building. Struct Environ 1:43-46

Zender - Świercz E, Piotrowski JZ (2010) Modification of microclimate in rooms equipped with individual air supply system (in polish). Fizyka budowli w teorii I praktyce (Building physics in theory and practice), vol V, no 1, Lodz, p 67-69

Zender - Świercz E, Piotrowski JZ (2011) Improving the microclimate inside the multi-family buildings (in Polish). Fizyka budowli $\mathrm{w}$ teorii i praktyce (Building physics in theory and practice), vol 6, no 4, Lodz, p 85-89 